\title{
6
}

\section{Surge Modeling in Sewers using the Transient Analysis Program (TAP)}

\author{
Karen E. Ridgway and Gregory J. Kumpula.
}

This chapter presents a new type of computational hydraulics program that is appropriate for simulating rapidly-varying transients (e.g. surges) in sewers. The hydraulics program was validated using experimental surge data in a pipeline obtained in a hydraulics laboratory. The validation data are presented along with two case study applications for the program.

The Transient Analysis Program (TAP) is a state-of-the-art computational hydraulics program that was developed to simulate steadystate, gradual time varying, and rapidly-varying flow conditions in a system of channels/conduits. TAP properly simulates the one-dimensional open channel, transitional and pressurized wave fronts that result from opening/closing gates, turning pumps $\mathrm{ON} / \mathrm{OFF}$, raising/lowering of inflatable dams and rapid filling. TAP was developed because the existing available computational programs commonly used for simulating sewer system hydraulics (e.g. EPA-SWMM, XP-SWMM, MOUSE and InfoWorks) do not properly represent the wave fronts and the resulting surges that are of concern during these situations.

TAP has been used to evaluate sanitary and combined sewer systems, CSO control facilities including capture and flow-through tunnel systems, and storm drains. Conduits with diameters that range from 4 inches to

Ridgway, K. and G.J. Kumpula. 2007. "Surge Modeling in Sewers using the Transient Analysis Program (TAP)." Journal of Water Management Modeling R227-06. doi: 10.14796/JWMM.R227-06.

(C) CHI 2007 www.chijournal.org ISSN: 2292-6062 (Formerly in Contemporary Modeling of Urban Water Systems. ISBN: 0-9736716-3-7) 
40 feet have been modeled with TAP. TAP is especially useful in analyzing deep relief sewers and tunnels. Rapid filling of these systems can result in the transitions from open channel to pressurized conditions with the creation of hydraulic bores. These hydraulic bores have steep wave fronts and can create surges in the hydraulic grade line (HGL) that rise above ground surface elevations. Surges are important to evaluate and control in deep relief sewers and tunnels since they can cause high internal pressures that can stress the conduit walls, and rise to grade and damage manholes, pavement and surface structures.

\subsection{General Description of TAP}

TAP solves the fully dynamic one-dimensional equations of continuity and momentum using a finite volume solution method. TAP simulates discontinuities in the HGL including open channel and pressure wave fronts using Roe's first order upwind scheme with an approximate Riemann solver.

TAP models include "links" that may be channels/conduits, gates, dams, or pumps. TAP requires that each "link" has a junction at each end. The channels/conduits in the system being analyzed are divided into uniformlyspaced cells. For each cell and for each time step, the fully dynamic equations are solved, and cell averaged quantities of depth, area, velocity, and flow rates are provided. Typically, the cell length is one-half to one times the conduit height/diameter for proper representation of surges. More than one channel/conduit may be connected to any junction, and the system being modeled may be branched or looped.

\subsection{Comparison to Other Programs}

TAP differs from many other computational hydraulics programs currently being used for the modeling of storm water, combined sewer and sanitary sewer systems. The major differences are listed below.

- Both the energy grade line (EGL) and the HGL are calculated throughout the system of channels/conduits and energy and volume are conserved at junctions.

- TAP properly simulates the discontinuities in HGL (wave fronts) that occur with open channel, closed conduit and 
transitional surge waves, including hydraulic bores and hydraulic jumps.

- TAP can simulate rapidly-varying transients under both open channel and closed conduit flow regimes, and transitions can occur freely between these regimes in the conduits.

- Once the conduits are surcharged, air may be allowed to enter the system only at user-specified junctions.

- Both laminar and wholly turbulent friction losses are estimated in the channels/conduits.

- Minor loss coefficients at channel/conduit ends at junctions may be user-specified with TAP and the coefficients can vary depending on the direction of flow.

- TAP includes many practical boundary conditions at junctions such as: outflow rating curves; constant or timevarying outflow; constant or time-varying EGL; constant or time-varying flow hydrograph inputs; storage volume modeled with a constant cross-sectional area or crosssectional area that varies with depth; and flooding allowed/disallowed to the ground surface elevation.

- TAP has the ability to simulate gate, pump and dam operations based on user specified operating rules. Constant speed and variable speed pumps with level or flow set points and ON/OFF levels can be specified.

\subsection{TAP Model Validation}

A physical model was set up in the University of Michigan hydraulics laboratory that included a nominal 4 inch diameter pipeline placed in a $50 \mathrm{ft}$ by $1 \mathrm{ft}(15 \mathrm{~m} \times 0.31 \mathrm{~m})$ open channel flume. At one end, the pipeline was connected to a fill box that overflowed at a level $0.777 \mathrm{ft}(0.236 \mathrm{~m})$ above the pipeline invert. A $0.825 \mathrm{ft}(0.251 \mathrm{~m})$ diameter riser was placed at the other end of the pipeline. A diagram of the physical set up is provided in Figure 6.1.

The pipeline was rapidly filled over a range of conditions. The filling rate, pipe slope and initial water depth in the pipeline were varied and the surges that occurred at the riser were observed and measured. 
TAP models of the physical set-up were developed and run for comparison. The only parameters that can be adjusted in the TAP models are Manning's $n$ values that are used to calculate friction losses in the pipe and minor loss coefficients for the ends of pipe. A textbook Manning's $n$ value equal to 0.010 was used for all of the model runs. Also, textbook minor loss factors were used for the entrance and exit losses at the pipe ends at the fill box and riser.

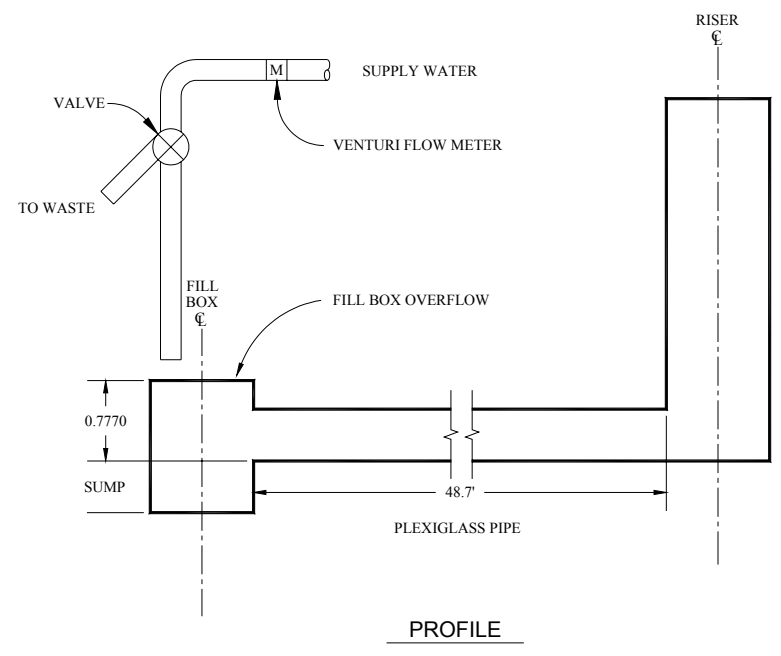

Figure 6.1 The physical model setup.

Table 6.1 shows the initial peak HGL and time of peak for a set of model runs for which the pipeline was level. For each model run, the initial depth of water in the pipe was varied. Model runs completed when the pipeline was sloped toward the fill box are shown in Table 6.2, and runs completed when the pipeline was sloped toward the riser are shown in Table 6.3. Figure 6.2 shows riser HGL versus time for a physical model run where up to four peaks and valleys were measured during the experiment.

The TAP model results agree well with the physical model results. The TAP model generally provides slightly conservative (high) surge heights. The experiments showed that the potential for trapping air pockets exists in the pipeline. Trapped air pockets, especially in Runs 10 through 14, occurred and dampen the surges and lengthen the period of oscillations. The largest surges were produced by bores moving uphill and the surges were greater in more steeply sloping pipes. 
Table 6.1 Physical model comparison for a level pipe.

\begin{tabular}{|c|c|c|c|c|c|}
\hline \multicolumn{3}{|c|}{ Test Date: } & \multicolumn{3}{|l|}{$6 / 12 / 01$} \\
\hline \multicolumn{3}{|c|}{ Pipe Slope in Percent: } & 0 & & \\
\hline \multicolumn{3}{|c|}{ Fill Box Invert Elevation (ft): } & 0 & & \\
\hline \multicolumn{3}{|c|}{ Riser Invert Elevation (ft): } & 0 & & \\
\hline \multicolumn{3}{|c|}{ Fill Rate (cfs): } & 0.125 & & \\
\hline & & \multicolumn{4}{|c|}{ Surge Results at Riser Shaft } \\
\hline & & \multicolumn{2}{|c|}{ TAP Model } & \multicolumn{2}{|c|}{ Physical Model } \\
\hline Run \# & $\begin{array}{c}\text { Initial } \\
\mathrm{HGL} \\
(\mathrm{ft}) \\
\end{array}$ & $\begin{array}{c}\text { Maximum } \\
\text { HGL } \\
(\mathrm{ft})\end{array}$ & $\begin{array}{c}\text { Time of } \\
\text { Peak } \\
(\mathrm{sec}) \\
\end{array}$ & $\begin{array}{c}\text { Maximum } \\
\text { HGL } \\
(\mathrm{ft})\end{array}$ & $\begin{array}{c}\text { Time of } \\
\text { Peak } \\
(\mathrm{sec})\end{array}$ \\
\hline 1 & 0.058 & 1.15 & 33.0 & 0.96 & Not Measured \\
\hline 2 & 0.190 & 1.46 & 17.5 & 1.44 & Not Measured \\
\hline 3 & 0.199 & 1.51 & 16.2 & 1.45 & Not Measured \\
\hline 4 & 0.288 & 1.30 & 9.7 & 1.22 & Not Measured \\
\hline
\end{tabular}

Table 6.2 Physical model comparison for a surge running uphill.

\begin{tabular}{|c|c|c|c|c|c|}
\hline \multicolumn{3}{|c|}{ Test Date: } & $6 / 14 / 01$ & & \\
\hline \multicolumn{3}{|c|}{ Pipe Slope in Percent: } & 0.07 & & \\
\hline \multicolumn{3}{|c|}{ Fill Box Invert Elevation (ft): } & 0 & & \\
\hline \multicolumn{3}{|c|}{ Riser Invert Elevation (ft): } & 0.034 & & \\
\hline \multicolumn{3}{|c|}{ Fill Rate (cfs): } & 0.128 & & \\
\hline & \multirow[b]{3}{*}{$\begin{array}{c}\text { Initial } \\
\text { HGL } \\
(\mathrm{ft}) \\
\end{array}$} & \multicolumn{4}{|c|}{ Surge Results at Riser Shaft } \\
\hline \multirow[b]{2}{*}{ Run \# } & & \multicolumn{2}{|c|}{ TAP Model } & \multicolumn{2}{|c|}{ Physical Model } \\
\hline & & $\begin{array}{c}\text { Maximum } \\
\text { HGL } \\
(\mathrm{ft})\end{array}$ & $\begin{array}{c}\text { Time of } \\
\text { Peak } \\
(\mathrm{sec}) \\
\end{array}$ & $\begin{array}{c}\text { Maximum } \\
\text { HGL } \\
(\mathrm{ft})\end{array}$ & $\begin{array}{c}\text { Time of } \\
\text { Peak } \\
(\mathrm{sec}) \\
\end{array}$ \\
\hline 5 & 0.137 & 1.26 & 25.2 & 1.16 & 24.0 \\
\hline 6 & 0.232 & 1.59 & 14.7 & 1.59 & 14.5 \\
\hline 7 & 0.248 & 1.62 & 13.2 & 1.61 & 13.5 \\
\hline 8 & 0.268 & 1.55 & 12.0 & 1.54 & 12.0 \\
\hline 9 & 0.278 & 1.50 & 11.2 & 1.48 & 11.5 \\
\hline
\end{tabular}


Table 6.3 Physical model comparison for a surge running downhill.

\begin{tabular}{lc}
\hline Test Date: & $10 / 3 / 01$ \\
Pipe Slope in Percent: & -0.34 \\
Fill Box Invert Elevation (ft): & 0 \\
Riser Invert Elevation (ft): & -0.166 \\
Fill Rate (cfs): & 0.145
\end{tabular}

Surge Results at Riser Shaft

\begin{tabular}{cccccc} 
& & \multicolumn{2}{c}{ TAP Model } & \multicolumn{2}{c}{ Physical Model } \\
\cline { 3 - 6 } & Initial & Maximum & Time of & Maximum & Time of \\
& HGL & HGL & Peak & HGL & Peak \\
$(\mathrm{ft})$ & $(\mathrm{ft})$ & $(\mathrm{sec})$ & 22.2 & 0.91 & 17.5 \\
\hline 10 & 0.019 & 1.03 & 15.7 & 1.34 & 14.3 \\
11 & 0.117 & 1.46 & 15.0 & 1.40 & 11.9 \\
12 & 0.154 & 1.42 & 13.0 & 8.2 \\
13 & 0.190 & 1.32 & 11.2 & 1.39 & Not Measured \\
\hline 14 & 0.245 & 1.24 & 9.7 & 0.97 & \\
\hline
\end{tabular}

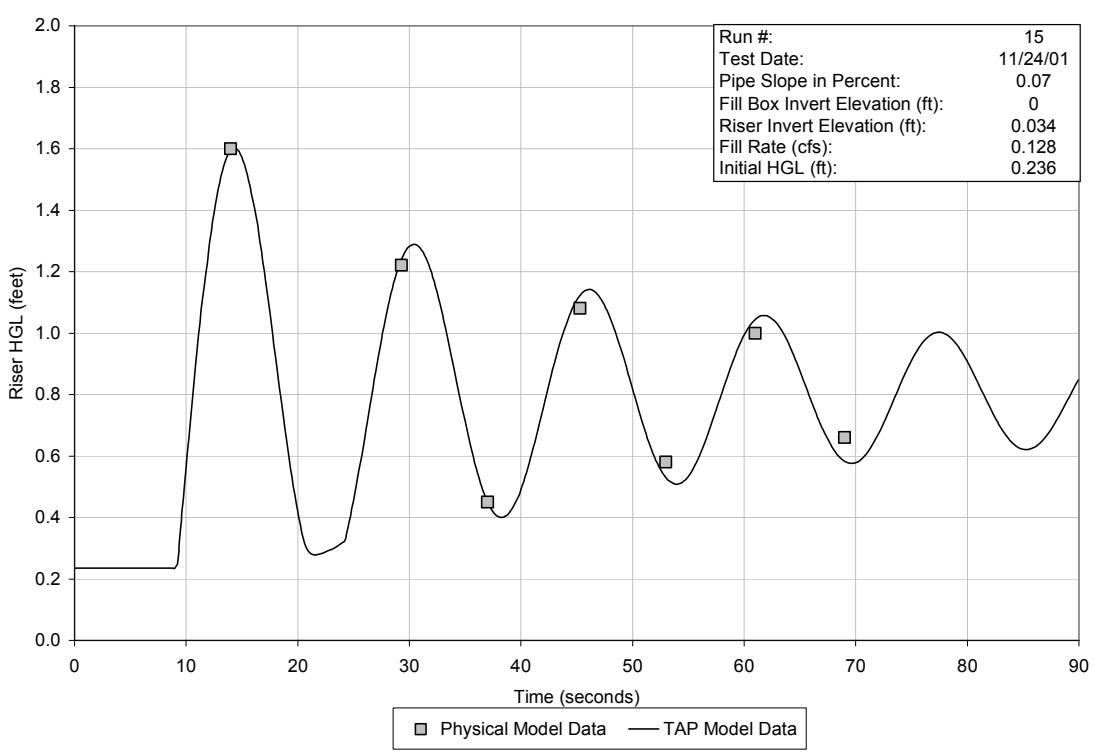

Figure 6.2 Riser HGL versus time for a sample comparison. 


\subsection{Bluehill P.S. Analysis}

A surge analysis was performed using TAP for a deep combined/relief sewer system downstream of the Bluehill Pump Station (P.S.) in Detroit, Michigan. Surges have occurred downstream of Bluehill P.S. primarily along the Mack Avenue relief sewer. These surges have lifted manhole covers, frames and cones, and damaged pavement and automobiles parked above manholes. In this study, the causes of the surges were investigated and improvements were evaluated and recommended to mitigate the surges. The downstream sewer system includes the Mack Avenue, Fox Creek, Ashland, East Jefferson and Manistique relief sewers as well as the Conner Creek and Freud P.S.

A TAP model of existing conditions was created in order to reproduce and investigate the sources of the surges. The TAP model schematic is given as Figure 6.3. This analysis included a complex, deep relief sewer network that includes the Bluehill P.S. discharging combined sewage to two other downstream combined sewer pump stations (Conner Creek and Freud P.S.). Flow inputs to the TAP model were obtained from a SWMM model for a range of design and historical storms. A 5-y, 24-h storm produced worst-case surges in the Bluehill P.S. system.

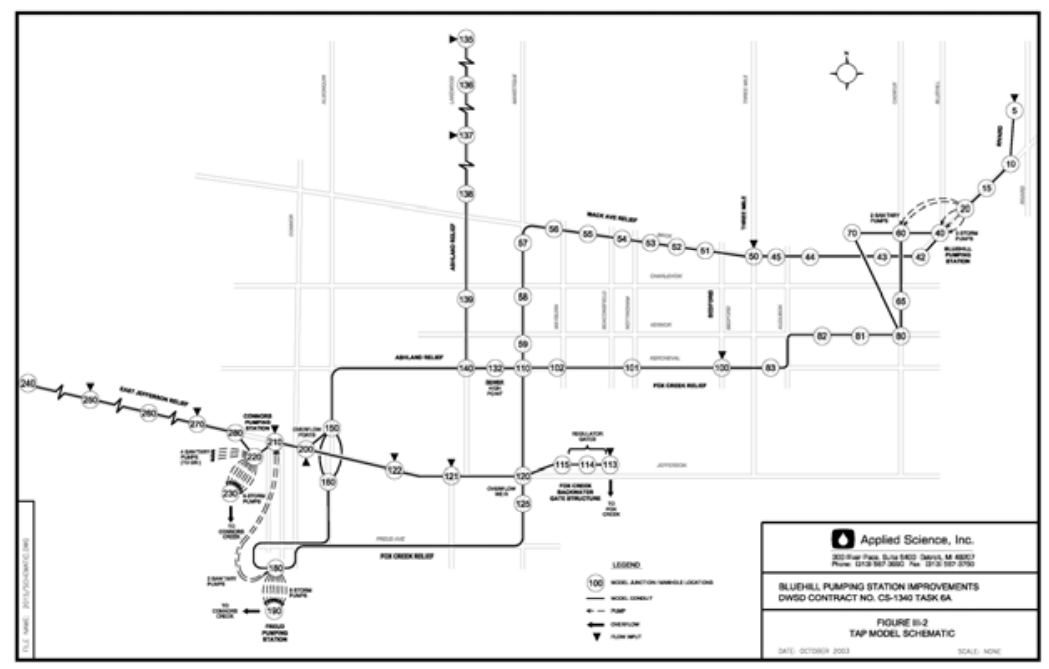

Figure 6.3 TAP model schematic for the Bluehill P.S. system. 
Three main causes of large surges were determined through a detailed analysis. During large rain events, Bluehill P.S. pumps were being started while the downstream sewers were becoming surcharged from backwater from the downstream Conner Creek and Freud P.S. Also, the Manistique sewer was filling with a backwater wave from Freud P.S. and after the peak of the rain event has passed, pumps at the Conner Creek and Freud P.S. were turning off with surcharged conditions in their upstream sewers. These factors combined to create large surges directly downstream of the Bluehill P.S. in the Mack Avenue relief sewer.

After the primary causes of surging were determined, alternative improvements were tested. The suggested improvements included: a minimum time between the second and third pump starts at the Bluehill P.S. of 20 minutes; lowering the existing weir wall between the East Jefferson and Manistique relief sewers, and a new overflow conduit between the Mack Avenue and Ashland relief sewers.

The suggested improvements offer a large reduction in surges through modifications to operational strategy and sewer system. TAP allowed the system to be evaluated and improvements to be analyzed for damaging surge conditions. Without a program such as TAP, this type of surge analysis would not have been possible.

\subsection{Upper Rouge Tunnel Surge Analysis}

The Upper Rouge Tunnel (URT) is a 7 mile $(11 \mathrm{~km})$ long CSO capture tunnel planned to be built about 140 to $190 \mathrm{ft}$ (43 to $58 \mathrm{~m}$ ) deep in rock along the Rouge River in Detroit, Michigan. Two tunnel segments were proposed for the URT due to geological considerations. The size of the upper tunnel segment was proposed with a diameter of $20 \mathrm{ft}(6.1 \mathrm{~m})$, and the lower tunnel segment was proposed with a diameter of $34.5 \mathrm{ft}(10.5 \mathrm{~m})$. This tunnel will be filled at drop shafts along its length. In order to protect the tunnel and its associated structures from damaging surge waves, surge control facilities are required. A schematic of the tunnel is given as Figure 6.4, and a profile of the proposed tunnel is given as Figure 6.5.

A TAP model of the URT was created in order to anticipate surge waves encountered during worst-case fast filling conditions. A front-loaded 10-y, 24-h design storm with wet antecedent conditions provided the fastest rise in flow rates and the highest peak flow rates possible from each of the CSO outfalls to be connected to the URT. The fast filling hydrographs were 
obtained from a SWMM model of the existing sewer system. The TAP model was used to develop and test control schemes and to determine the surge control facilities required for the URT.

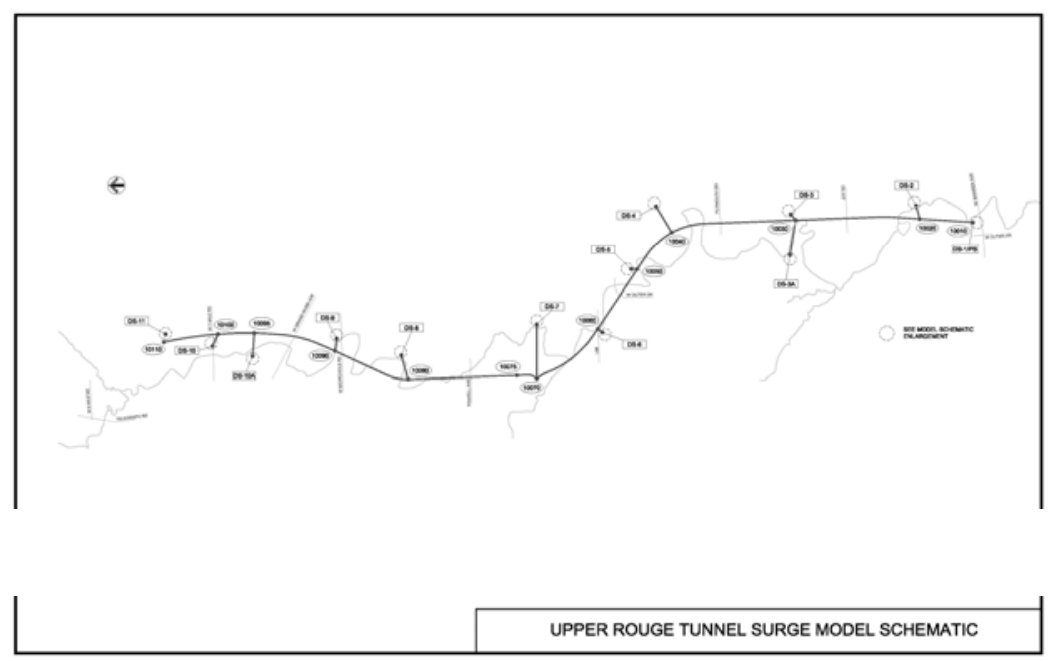

Figure 6.4 Schematic of the proposed tunnel.

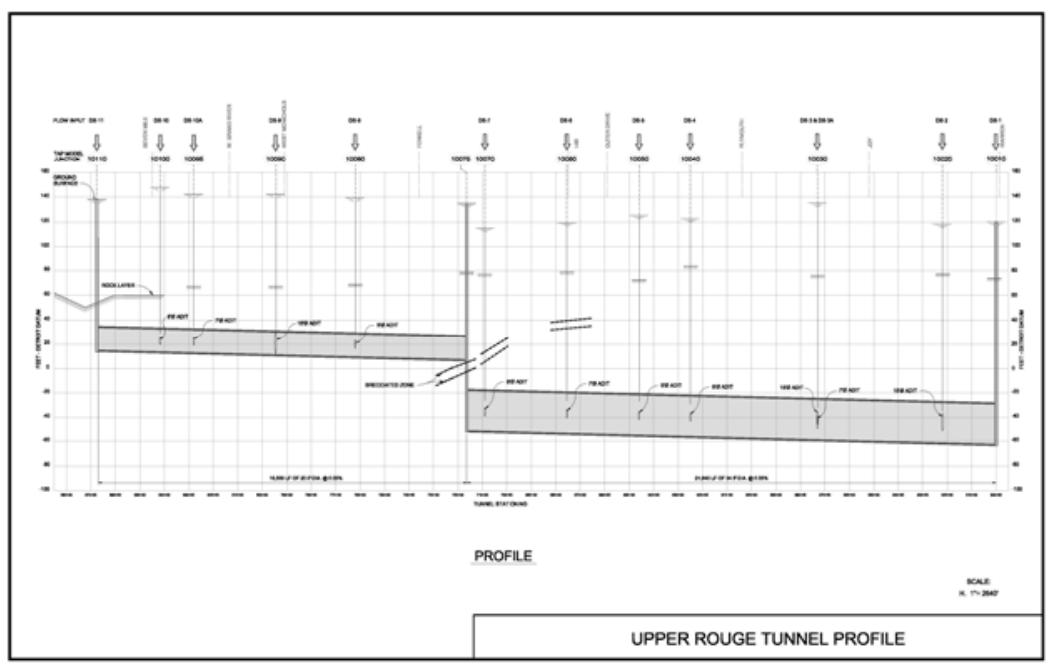

Figure 6.5 Profile of the proposed tunnel. 
The tunnel is planned to be operated with a passive control scheme. The URT will receive flow from $17 \mathrm{CSO}$ outfalls through diversion chamber connections and 13 drop shafts. For the passive control scheme, flap gates will be placed in each diversion chamber and will close once the HGL in the URT exceeds the HGL in the CSO outfall. The flap gates will only close once the tunnel is completely filled with CSO. When the flap gates close, surges will be created and contained within the URT system. Surge tanks that are named Surge Control Volumes (SCVs) are proposed to be connected to each diversion/drop chamber to store the expected maximum surge wave. The SCV overflow levels are all at the same level to prevent flow-through operation of the URT. The SCV overflow level was set to be slightly greater than the highest peak HGL expected in the existing CSO outfalls connected to the URT. A typical schematic of a diversion/drop structure is given as Figure 6.6, and shows a typical SCV set-up.

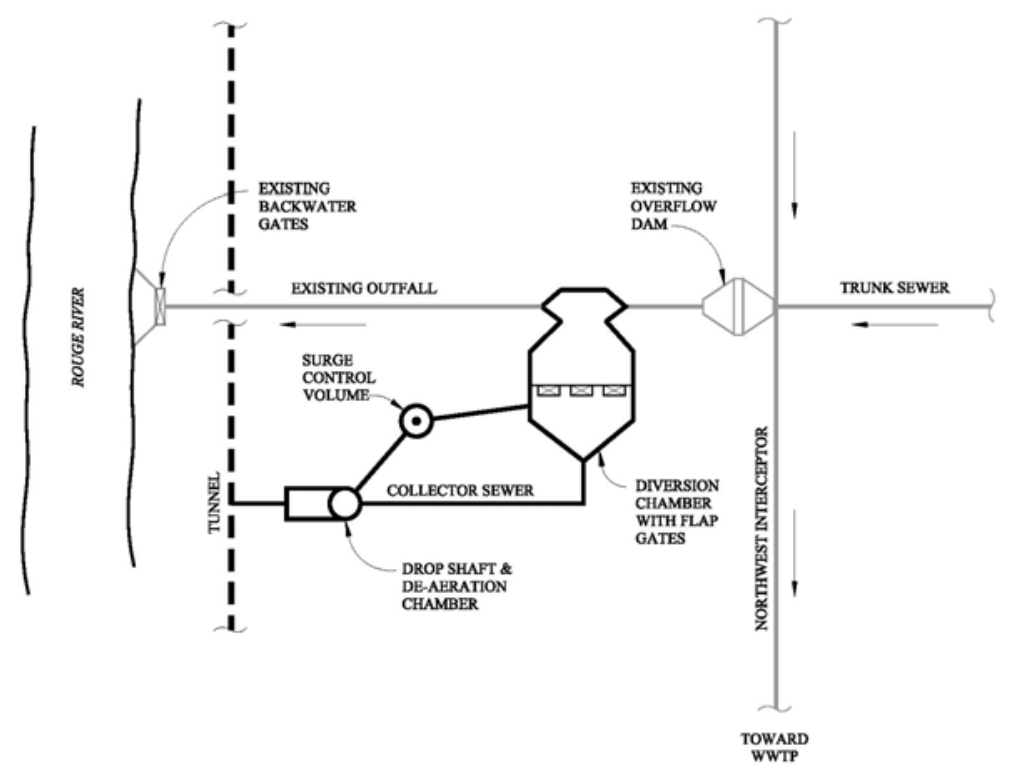

Figure 6.6 A typical URT facility schematic.

The TAP model of the URT was used to evaluate alternative fast filling conditions. The tunnel was filled uniformly from all connections along its length, as well as only from the upstream and downstream segment 
connections. These alternative filling conditions were used to determine a range of surge conditions for the URT.

The downstream only fast filling condition creates larger surges at the upstream end of the tunnel. This result is due the large wave traveling into the upstream section of the tunnel crashing into the upstream end of the tunnel. Results such as these show the importance of a detailed and thorough surge analysis.

The TAP model runs were used to determine the SCV volumes required to mitigate surges for the alternative filling conditions. The storage requirement at each SCV was determined by selecting the maximum result from the alternative model runs. These volumes are given as Table 6.4.

Table 6.4 SCV requirements.

\begin{tabular}{|c|c|c|c|c|c|c|c|c|}
\hline \multirow[t]{2}{*}{$\begin{array}{l}\text { Overflow } \\
\text { Location }\end{array}$} & \multicolumn{2}{|c|}{$\begin{array}{l}\text { Uniform Fast } \\
\text { Fill Condition }\end{array}$} & \multicolumn{2}{|c|}{$\begin{array}{r}\text { Downstream } \\
\text { Fast Fill } \\
\text { Condition }\end{array}$} & \multicolumn{2}{|c|}{$\begin{array}{c}\text { Upstream Fast } \\
\text { Fill Condition }\end{array}$} & \multicolumn{2}{|c|}{$\begin{array}{r}\text { Maximum } \\
\text { Result }\end{array}$} \\
\hline & $\begin{array}{l}\text { Qpeak } \\
\text { (cfs) }\end{array}$ & $\begin{array}{l}\text { Max } \\
\text { Vol. } \\
\text { (mg) }\end{array}$ & $\begin{array}{l}\text { Qpeak } \\
\text { (cfs) }\end{array}$ & $\begin{array}{l}\text { Max } \\
\text { Vol. } \\
\text { (mg) }\end{array}$ & $\begin{array}{l}\text { Qpeak } \\
\text { (cfs) }\end{array}$ & $\begin{array}{l}\text { Max } \\
\text { Vol. } \\
(\mathrm{mg})\end{array}$ & $\begin{array}{l}\text { Qpeak } \\
\text { (cfs) }\end{array}$ & $\begin{array}{l}\text { Max } \\
\text { Vol. } \\
\text { (mg) }\end{array}$ \\
\hline Pumping Station & 1414 & 2.85 & 353 & 2.84 & 674 & 2.83 & 1414 & 2.85 \\
\hline Warren DC & 564 & 0.24 & 0 & 0.00 & 86 & 0.08 & 564 & 0.24 \\
\hline Tireman DC & 1408 & 0.43 & 0 & 0.00 & 222 & 0.20 & 1408 & 0.43 \\
\hline W. Chicago DC & 329 & 0.08 & 0 & 0.00 & 141 & 0.08 & 329 & 0.08 \\
\hline $\begin{array}{l}\text { W. Chicago } \\
\text { Siphon DC }\end{array}$ & 114 & 0.04 & 0 & 0.00 & 124 & 0.07 & 124 & 0.07 \\
\hline Glendale DC & 256 & 0.07 & 0 & 0.00 & 141 & 0.09 & 256 & 0.09 \\
\hline Lahser DC & 339 & 0.07 & 0 & 0.00 & 165 & 0.08 & 339 & 0.08 \\
\hline $\begin{array}{l}\text { W. Parkway / } \\
\text { Schoolcraft DC }\end{array}$ & 163 & 0.03 & 0 & 0.00 & 124 & 0.05 & 163 & 0.05 \\
\hline Lyndon DC & 300 & 0.11 & 0 & 0.00 & 248 & 0.13 & 300 & 0.13 \\
\hline Puritan DC & 6 & $<0.01$ & 266 & 0.06 & 0 & 0.00 & 266 & 0.06 \\
\hline Six Mile DC & 0 & 0.00 & 1920 & 0.51 & 0 & 0.00 & 1920 & 0.51 \\
\hline Glenhurst DC & 0 & 0.00 & 236 & 0.12 & 0 & 0.00 & 236 & 0.12 \\
\hline Seven Mile DC & 0 & 0.00 & 644 & 0.45 & 0 & 0.00 & 644 & 0.45 \\
\hline Frisbee DC & 0 & 0.00 & 2498 & 2.36 & 0 & 0.00 & 2498 & 2.36 \\
\hline Total Volume & - & 3.92 & - & 6.34 & - & 3.61 & - & 7.52 \\
\hline
\end{tabular}




\subsection{Conclusions}

Rapidly-varying flow conditions commonly occur in combined and storm sewer systems during storm conditions. TAP includes a solution technique that properly calculates rapidly-varying flow conditions in open channel, closed conduit and transitional conditions including hydraulic bores. TAP is a useful tool to evaluate surges in sewer systems, especially those caused by pump operation and rapid filling. Without a program such as TAP, a proper analysis of rapidly-varying conditions and the resulting surge waves is not possible.

\section{Acknowledgments}

Ms. Karen E. Ridgway, P.E. created TAP beginning in the summer of year 2000 with programming assistance from Mr. Gregory J. Kumpula, P.E. TAP was originally created with an internal finite volume solution method that was provided by Nik Katopodes, Ph.D, P.E., a professor in the Civil and Environmental Engineering (CEE) Department at the University of Michigan. This method has been presented in the graduate level open channel hydraulic transient class at the University of Michigan and in several technical papers and journal articles. Mr. Steven J. Wright, Ph.D., P.E., another professor of CEE at the University of Michigan, provided surge model data from the University's hydraulic laboratory. The laboratory data were used to verify the validity of TAP. Mr. Jose Goes Vasconcelos, Ph.D. a 2005 graduate of the University of Michigan conducted the laboratory experiments, provided peer reviews of TAP and suggested program improvements. His doctoral research involved the study of surges and air/water interfaces in pressurized conduits.

\section{References}

Cardle, J. A. and Song, C. S. S. (1988). "Mathematical modeling of unsteady flow in storm sewers." Int. J. Engrg. Fluid Mech., 1(4), 495-518.

Crossley, A. J. (2003). "Local time stepping for modeling open channel flows." J. Hydr. Engrg., 129(6), 455-462.

Macchione, F. and Morelli, M. A. (2003). "Practical aspects in comparing the shockcapturing schemes for dam break problems.” J. Hydr. Engrg., 129(3), 187-195. 
Preissmann, A. (1961). "Propagation des intumescences dans les canaux et rivières", 1st Congress of the French Association for Computation (AFCALTI), September, Grenoble.

Roe, P. L. (1981). "Approximate Riemann solvers, parameter vectors, and difference schemes." J. Comp. Physics, 43, 357-372.

Song, C. S. S., Cardle, J. A., and Leung, K. S. (1983). "Transient mixed-flow models for storm sewers." J. Hydr. Engrg., 109(11), 1487-1504.

Sturm, T., 2001. Open Channel Hydraulics, 1st Edition. McGraw-Hill, New York, NY.

Toro, E. F., August 2001. Shock-Capturing Methods for Free-Surface Shallow Flows. John Wiley and Sons.

Vasconcelos, J. (2005). Doctoral dissertation.

Wiggert, D. C. (1972). "Transient flow in free-surface, pressurized systems." J. Hydr. Div., 98(HY1), 11-27.

Yen, B. C., 2001. Hydraulic of sewer systems. In: Mays, L. W. (Ed.), Stormwater Collection Systems Design Handbook. McGraw Hill Handbooks. McGraw-Hill, NewYork, Ch. 6.

Report, University of California at Santa Barbara, CA. 
